\title{
Participation of Drosophila melanogaster alcohol dehydrogenase (ADH) in the detoxification of 1-pentene-3-ol and 1-pentene-3-one
}

J. J. Garrido, G. Dorado and M. Barbancho*
Departamento de Genética, Facultad de Ciencias, Universidad de Córdoba, E-14071 Córdoba, Spain.

The participation of the ADH enzymes in the detoxification by $D$. melanogaster of 1-pentene-3-ol (also called pentenol) and its oxidized product, 1-pentene-3-one (usually known as ethyl-vinyl-ketone or pentenone) have been studied using the LR lines. For this purpose flies of $A d h^{\mathrm{S}} A d h^{\mathrm{S}}$ (SS) and $A d h^{\mathrm{F}} A d h^{\mathrm{F}}$ (FF) genotypes were independently pretreated with a 2 per cent isopropanol (2-propanol) solution and the survivors exposed to water, to a 0.0075 per cent pentenol solution or to a 0.00375 per cent pentenone solution. After one day in these solutions, the ability to tolerate both compounds was checked and the ADH activity of the surviving flies was measured and compared with those of control flies not pretreated with isopropanol. Additionally, the effects of pentenone on ADH enzymes have been studied by comparing them with those of acetone.

Our results show that, in contrast to acetone, pentenone neither reduced significantly the $\mathrm{ADH}$ activity in vivo nor altered the normal proportion of ADH isozymes of either SS or FF flies. Our findings also demonstrate that the isopropanol pretreatment implied a considerable decrease in sensitivity not only to pentenol (60 and 91 per cent for SS and FF flies, respectively) but also to pentenone (72 and 80 per cent for SS and FF flies, respectively). After isopropanol pretreatment, FF flies continued exhibiting higher ADH activities than SS ones. However, FF pretreated flies displayed higher tolerance to pentenol and a similar tolerance to pentenone than SS animals.

Our results suggest that pentenol (unsaturated secondary alcohol) and isopropanol (saturated secondary alcohol) may be detoxified by slightly different processes (both ADH-activity-dependent), and that pentenone could not be accumulated in the fly but transformed into another compound(s) by means of some ADH-independent mechanism(s).

\section{INTRODUCTION}

Drosophila melanogaster alcohol dehydrogenase isozymes $(\mathrm{ADH})$ can use several alcohols as substrates (Day et al., 1974; Morgan, 1975). ADH enzymes catalyze the oxidation of primary and secondary alcohols into aldehydes and ketones, respectively. However, while aldehydes are further metabolized by means of an aldehyde dehydrogenase (David et al., 1984) and/or the ADH itself (Heinstra et al., 1983, 1986b; Eisses et al., 1985; Moxom et al., 1985), ketones seem to be metabolic dead ends (David et al., 1981; Heinstra et al., 1986a). In fact, primary alcohols can be used by Drosophila as food, while secondary ones cannot (van Herrewege et al., 1980; Sánchez-Cañete et al., 1986).

On the other hand, during the oxidation of secondary alcohols in Drosophila, ADH forms a

\footnotetext{
* To whom correspondence and reprint requests should be sent.
}

ternary complex with NAD and ketones, which is associated with a strong inhibition of $\mathrm{ADH}$ activity. The formation of such an inhibitory product is also associated with variation in the ratio of the ADH isozymes, which can be monitored by a conversion in the electrophoretic ADH patterns (Anderson and McDonald, 1981b; GonzàlezDuarte and Atrian, 1986; Heinstra et al., 1986a, b; Guillén et al., 1987).

It can be assumed that the variations in ADH activity are likely to cause functional differences in metabolic flux, and therefore affect the toxic effects of environmental alcohols. Thus, flies with higher ADH activity levels should be more sensitive to secondary alcohols than flies with lower ADH activity. However, it is well known that ADH-FF flies are more tolerant to isopropanol than ADH-negative (David et al., 1981) or ADHSS (Sánchez-Cañete et al., 1986) flies. Middleton and Kacser (1983) found no relation between the 
metabolic flux (in the conversion of ethanol to $\mathrm{CO}_{2}$ and lipids) and the ADH activity.

Pentenol (1-pentene-3-ol) is a secondary unsaturated alcohol which seems to be oxidized in vivo by alcohol dehydrogenase into pentenone (1pentene-3-one or ethyl-vinyl-ketone) (Sofer and Hatkoff, 1972). Pentenone does not appear to be metabolized by Drosophila and its accumulation is highly toxic to flies. In fact, secondary unsaturated alcohols have been used for screening and isolation of ADH-negative mutants (Sofer and Hatkoff, 1972; O'Donnell et al., 1975).

If $\mathrm{ADH}$ transforms pentenol into pentenone in vivo and if the later compound does accumulate in the fly, a reduction of ADH activity levels must imply a decrease in the sensitivity to pentenol but not to pentenone. However, acetone, the product of the oxidation of isopropanol (another secondary but saturated alcohol) by the enzyme $\mathrm{ADH}$, is better detoxified by ADH-active flies than by ADH-negative ones (David et al., 1981). Nevertheless-as pointed out before-acetone rapidly inhibits ADH activity.

In order to detect the possible differences in the ADH-mediated detoxification of the two secondary alcohols (isopropanol and pentenol) by $D$. melanogaster we studied the role of ADH isozymes in the detoxification of pentenol and its oxidized product (pentenone). We compared the sensitivity to both chemicals of flies with reduced or normal ADH activities, and also assessed the possible effects of pentenone on ADH isozymes.

\section{MATERIALS AND METHODS}

\section{Drosophila strains}

Two LR strains of Drosophila melanogaster were used: one homozygous for the $A d h^{\mathrm{s}}$ allele (SS) and the other homozygous for the $A d h^{\mathrm{F}}$ allele (FF). Each strain was obtained by intercrossing 15 homozygous stocks of the appropriate genotype which came originally from a single sample collected in the "Lagar de los Reyes", a winery in Córdoba (Spain). The strains used had previously been selected for tolerance to ethanol (LRSe). Further details about the strains and culture conditions have been described elsewhere (Dorado and Barbancho, 1984).

\section{Experimental procedures}

Flies from each strain were independently raised on normal food for one generation. After the emergence of the adults, two-day-old flies of each genotype were divided into two groups. One group was maintained on normal food and the other on a 2 per cent isopropanol-supplemented food. After one day on these media, survivors of each group were exposed to water, to a 0.0075 per cent pentenol solution or to a 0.00375 per cent pentenone solution in hermetically closed vials. After one day more in these solutions, the mortality and the ADH activity of survivors were determined. Adult mortality was measured in hermetically closed vials containing $3 \mathrm{ml}$ of the appropriate solution. A minimum set of three replicates were tested for each condition, each vial containing 10 males and 10 females. For further details see Sánchez-Canete et al. (1986).

ADH activity was determined by following the reduction of $\mathrm{NAD}^{+}$at $340 \mathrm{~nm}$ according to Barbancho et al. (1987), with the exception that samples of 20 adults (males or females, separately) were used. One unit of ADH activity is defined as the amount of enzyme which reduces $1 \mu \mathrm{mol}$ of $\mathrm{NAD}^{+}$per minute under assay conditions.

To reduce the ADH activity in vivo, in addition to the isopropanol pretreatment referred to above, groups of 20 three-day-old flies were kept for one day in hermetically closed vials containing $3 \mathrm{ml}$ of a 0.5 per cent acetone solution.

Finally, to detect the different molecular forms of the ADH allozymes, starch gel electrophoresis of the appropriate homogenates of flies was carried out according to Ayala et al. (1972).

\section{RESULTS}

\section{$A D H$ activity and electrophoretic patterns of flies exposed to pentenone}

The effects of pentenone and acetone on both the electrophoretic patterns and the activity of ADH allozymes are shown in figs. 1 and 2, respectively.

As expected, ADH allozymes of flies exposed to acetone were clearly "interconverted" towards ADH-1 forms. However, ADH allozymes of flies exposed to pentenone did not show significant changes in the electrophoretic pattern at the concentrations used (fig. 1). The same results were observed when flies were exposed to pentenol (data not shown). Nevertheless, faint bands corresponding to the ADH-1 form were observed when FF flies were exposed to pentenone at the highest concentrations tested (fig. 1).

However, while acetone provokes a considerable decrease in total ADH activity, pentenone does not appear to induce significant changes (fig. 2). In fact, only a weak decrease in ADH activity 


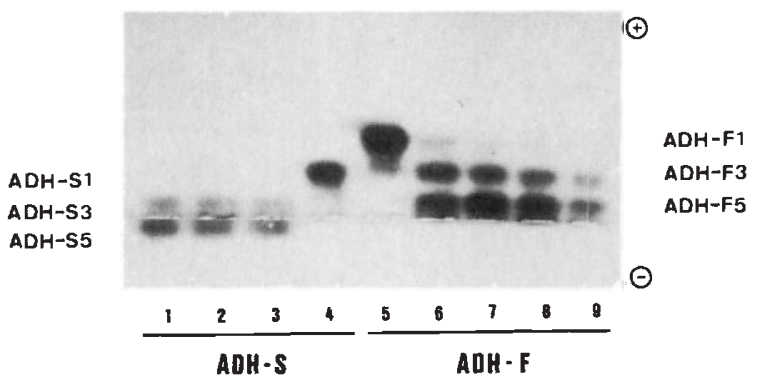

Figure 1 Electrophoretic patterns of $\mathrm{ADH}-\mathrm{S}$ and $\mathrm{ADH}-\mathrm{F}$ allozymes from extracts of surviving flies after one day of exposure to water $(1,9)$, to pentenone at concentrations of 0.00375 per cent $(2,8), 0.0045$ per cent $(3,7)$ and 0.0075 per cent $(6)$, and to acetone at a concentration of 0.5 per cent $(4,5)$.

was observed in FF flies exposed to pentenone ( 7 per cent), which seems to be in accordance with the pale ADH-1 bands detected in the zymogram. Moreover, it must be pointed out that the decrease in ADH activity observed in FF flies does not correlate with the concentration of pentenone used, because the individuals exposed to pentenone at the lowest and at the highest concentrations exhibited the same ADH activity. It is poss-

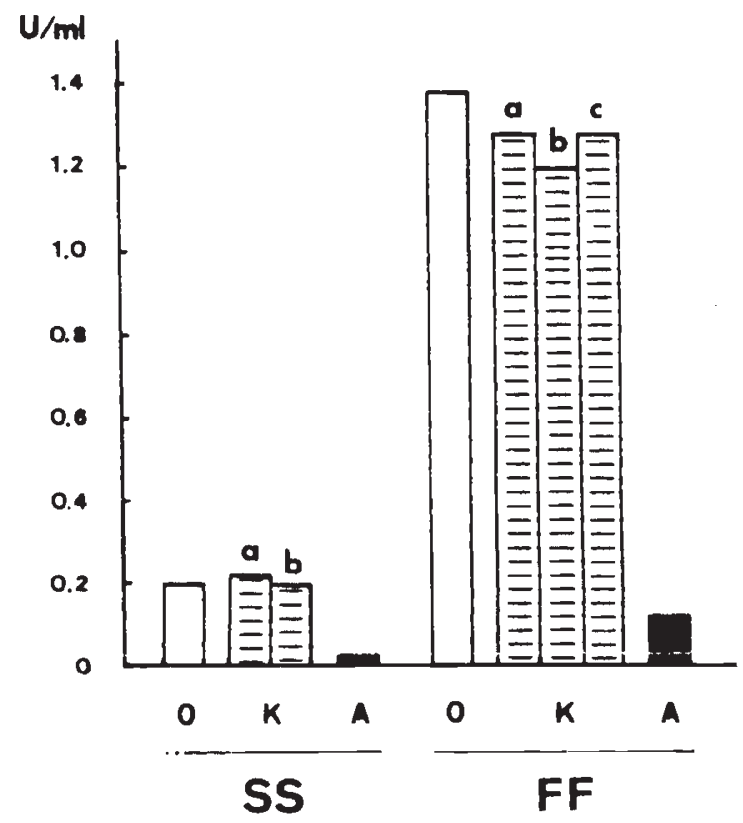

Figure 2 ADH activities $(\mathrm{U} / \mathrm{ml})$ from extracts of surviving flies of SS and FF genotypes after one day of exposure to water $(0)$, to pentenone $(\mathrm{K})$ at concentrations of 0.00375 per cent (a), 0.0045 per cent (b) and 0.0075 per cent (c), and to acetone $(\mathrm{A})$ at a concentration of 0.5 per cent. ible that pentenone at even greater concentrations could induce a greater ADH activity reduction. Nevertheless, such concentrations would be highly toxic to the flies. In fact, FF individuals exposed to 0.0075 per cent pentenone manifested a mortality of 78 per cent, while the same flies exposed to 0.5 per cent acetone exhibited a mortality of 20 per cent.

\section{Effects of an isopropanol pretreatment on $A D H$ activity and mortality of flies exposed to pentenol or pentenone}

Fig. 3 shows the ADH activities and mortalities of males and females of SS and FF $A d h$ genotypes after different exposures. Due to the fact that males of both $A d h$ genotypes manifested a high mortality in some solutions, the complete analysis was only performed with the females.

Table 1 indicates the percentage changes in ADH activity and mortality of the flies under different conditions.

After one day of exposure to pentenol (0.P) or pentenone $(0 . \mathrm{K})$ mortalities of both SS and FF flies from the control group were very high (nearly 100 per cent) when compared to those on water (0.0) (0 per cent) (fig. 3).

As expected, ADH activity dramatically decreased when flies of both SS and FF genotypes were transferred to isopropanol-supplemented food (I). As it was also expected, ADH activity was partially recovered when the isopropanol pretreated flies were transferred for one day to water (I . 0). ADH activity also increased when flies previously treated with isopropanol were exposed to either pentenol (I.P) or pentenone (I.K), although in these cases the rise was only observed in FF flies (fig. 3). However, I. P and I. K flies from both genotypes continued exhibiting $\mathrm{ADH}$ activities very reduced if they are compared with those of $0 . \mathrm{P}$ and $0 . \mathrm{K}$ flies (table 1).

Additionally, when the flies were exposed to pentenol, the isopropanol pretreated individuals displayed a much lower mortality than the nonpretreated ones (table 1: 0.P vs. I. P, and fig 3). This is not surprising, as it is known that in vivo ADH oxidizes pentenol into pentenone, a compound much more toxic than the former. Thus, a reduction in $\mathrm{ADH}$ activity implies a parellel decrease in mortality of the flies exposed to pentenol. Nevertheless, and somewhat surprisingly, isopropanol pretreated flies also exhibited a mortality much lower than their respective controls when they were exposed to pentenone (table 1: 0 . K vs. I. K, and fig. 3 ). 


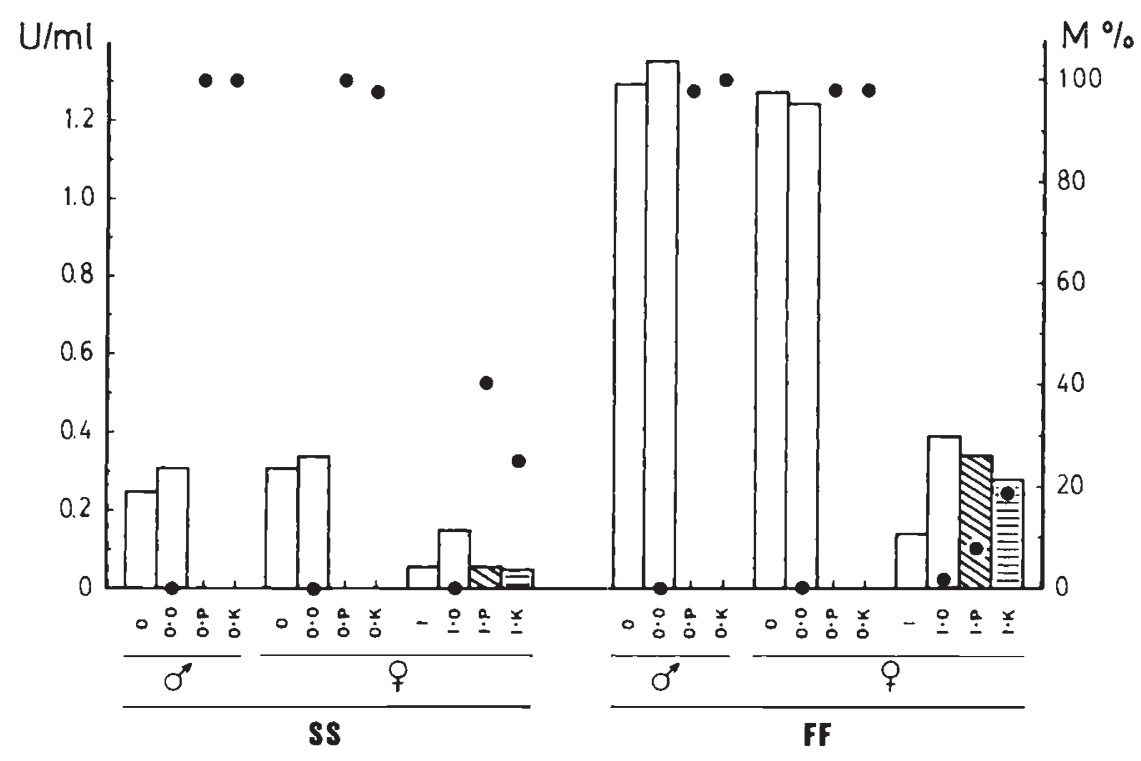

Figure 3 ADH activities in $U / \mathrm{ml}(\square, \mathbb{Q}$, 自) and percentages of mortalities $(\bigcirc)$ of SS and FF flies. The adults were kept one day on normal food $(0)$ or on a 2 per cent isopropanol-supplemented normal food (I). Then the flies were transferred to distilled water $(0.0$, I .0), to a 0.0075 per cent pentenol solution (0. P, I . P) or to a 0.00375 per cent pentenone solution ( 0 . K, I . K). Thus, the experiments were carried out without (0.) and with (I.) a previous exposure of flies to a 2 per cent isopropanol solution for one day.

The data in fig. 3 suggest a genotypic effect within each one of the tested groups. Thus, SS and FF flies without isopropanol pretreatment showed a marked difference in ADH activity (FF higher than SS), but this did not imply differences in their mortalities either on pentenol $(0 . P)$ or on pentenone $(0 . \mathrm{K})$ at the concentrations used. However, in the case of isopropanol pretreated

Table 1 Percentages of reductions in ADH activity and in mortality of females from SS and FF $A d h$ genotypes under different conditions

\begin{tabular}{lllc}
\hline Genotype & Comparison & $\begin{array}{l}\text { ADH } \\
\text { Activity }\end{array}$ & Mortality \\
\hline \multirow{2}{*}{ SS } & 0.0 vs. I. . & 53 & 0 \\
& 0.P vs. I. P & 84 & 60 \\
& 0.K vs. I. K & 84 & 72 \\
FF & 0.0 vs. I. . & 68 & -2 \\
& 0.P vs. I. P & 73 & 91 \\
& 0. K vs. I. K & 77 & 80 \\
\hline
\end{tabular}

Data for ADH activities represent the differences between the values found under the two conditions compared, expressed as percentages of the value found under the first experimental condition. Data for mortalities represent the differences between the mortality percentages found under the two conditions compared.

For abbreviations of the exposure conditions see legend of fig. 3 . flies, FF females manifested a lower mortality on pentenol (I . P) than SS flies $(t=5 \cdot 206 ; P<0 \cdot 001)$, although the ADH activity of FF was much more higher than that of SS. In contrast, both FF and SS females pretreated with isopropanol exhibited similar mortalities when they were further exposed to pentenone (I.K) $(t=0.900 ; P>0.05)$, though FF extracts were again more active than SS ones.

\section{DISCUSSION}

In Drosophila, ADH catalyses the oxidation of alcohols into their corresponding aldehydes or ketones, being the oxidized products usually more toxic than their respective alcohols (Day et al., 1974; David et al., 1978, 1981; Heinstra et al., 1983; Gonzàlez-Duarte and Atrian, 1986). To test the role played by $\mathrm{ADH}$ allozymes in the detoxification by $D$. melanogaster of pentenol and pentenonetwo very toxic compounds-we compared flies of both SS and FF Adh genotypes exhibiting standard ADH activities, with flies whose ADH activities had been diminished with an isopropanol pretreatment (fig. 3 and table 1). Our results show that in both Adh genotypes, a reduction in ADH activity implies a considerable decrease in sensitivity to pentenol (60 per cent for SS and 91 per cent for FF). These results are in agreement with those of 
Papel et al. (1979) who observed that the exposure of flies to a 0.5 per cent acetone resulted in a concomitant insensitivity to further pentenol treatment, as a consequence of the loss of ADH activity. Obviously, these results suggest the participation of the ADH allozymes in the metabolism of pentenol in D. melanogaster. ADH seems to transform pentenol into pentenone, which is a compound two to three times more toxic than the former (data not shown). Consequently, a decrement of ADH activity is accompanied by a lower sensitivity to pentenol as a consequence of the reduction in the rate of pentenone production. However, we cannot assume, as other authors do (Sofer and Hatkoff, 1972; Morgan, 1975; Oakeshott, 1977), a simple inverse relationship between $\mathrm{ADH}$ activity and tolerance to pentenol, because of the fact that after isopropanol pretreatment, FF flies continued showing higher ADH activities than SS ones, but the former (FF) were also significantly more tolerant to pentenol than the later (SS) (fig. 3). Other enzymes, besides $\mathrm{ADH}$, must presumably participate in the metabolism of pentenol. This idea is also supported by the results obtained after exposing Drosophila to pentenone (fig. 3 and table 1). Flies of both $A d h$ genotypes with previously reduced ADH activity, also exhibited a considerable decrease in sensitivity to pentenone ( 72 per cent for SS and 80 per cent for FF). It could be argued that $\mathrm{ADH}$ might transform pentenone into another more toxic compound. But in that case, after a previous $\mathrm{ADH}$ activity reduction, the FF flies-which display higher ADH activity than the SS ones, should be more sensitive to pentenone than SS flies. Nevertheless, our results demonstrate that after exposure to the ketone the mortality is similar for both genotypes (fig. 3). An ADH reverse reaction, by means of which ketones would be transformed into alcohols, has been suggested (David et al., 1981) and even described (GonzàlezDuarte and Vilageliu, 1984). However, ADH does not seem to detoxify the pentenone, transforming it into pentenol, since isopropanol pretreatment reduces both the $\mathrm{ADH}$ activity and the sensitivity to pentenone (fig. 3 and table 1).

Gonzàlez-Duarte and Atrian (1986) have reported that an exposure to isopropanol of $D$. hydei causes a marked decrease in $\mathrm{ADH}$ activity and a clear increase in aldo-keto-reductase (AKR) activity. AKR can use acetone as substrate, converting it into isopropanol. If $\mathrm{AKR}$ recognizes carbonyl groups then it could be possible for such an enzyme to convert pentenone into pentenol. If this is so, and if isopropanol induces AKR activity in $D$. melanogaster, then the reduction in mortality on pentenol solutions of the flies pretreated with isopropanol could be explained by the facts that the loss in ADH activity would reduce the production of pentenone, while the increase in AKR activity would transform the pentenone into pentenol. Both processes would diminish the toxic effects of pentenone. Similarly, the decrease in mortality on pentenone solutions of flies pretreated with isopropanol could be explained by the transformation of pentenone into pentenol, catalized by the increased AKR activity. However, after isopropanol pretreatment, FF flies exhibited higher ADH activity but lower or similar mortality on pentenol and pentenone, respectively, than SS individuals (fig. 3). Thus, a genotype-dependent AKR activity induction would have to be involved.

Oakeshott (1977) has suggested a further metabolism of the pentenone produced by the action of $\mathrm{ADH}$ on pentenol. He has argued that the beneficial effect of pentenol in reducing the developmental times of flies from five $A d h$ genotypes grown on such alcohol possibly derives from subsequent pathways to the ADH-mediated production of pentenone.

Another possibility is that pentenone could be partially excreted-unchanged-to the external medium by a mechanism whose effectiveness was enhanced by the isopropanol pretreatment. In fact, Gonzàlez-Duarte and Atrian (1986) have found that when adult flies of $D$. hydei are exposed to isopropanol, the external acetone concentration rises progressively while the internal one increases during the first 72 hours and then decreases.

However, the processes of detoxification of both secondary alcohols (unsaturated pentenol and saturated isopropanol) do not seem to be similar, although in both cases the ADH enzymes are implicated. First of all, our results show that while acetone causes a dramatic decrease of total $\mathrm{ADH}$ activity in vivo, which is in agreement with earlier results (Papel et al., 1979; Anderson and McDonald, $1981 b$; Gonzàlez-Duarte and Atrian, 1986; Heinstra et al., 1986c; Guillén et al., 1987), pentenone does not seem to change significantly the ADH activity of flies exposed to it (fig. 2). While acetone induces an "interconversion" of $\mathrm{ADH}$ isozymes towards the more electronegative form (ADH-1), which is in agreement with earlier observations (Schwartz and Sofer, 1976; Papel et al., 1979; Schwartz et al., 1979; Vilageliu and Gonzàlez-Duarte, 1980; Anderson and McDonald, 1981a; Heinstra et al., 1986a, c; Guillén et al., 1987), neither pentenol nor pentenone produce significant changes in vivo in the standard $\mathrm{ADH}$ electrophoretic pattern (fig. 1). Additionally, while 
flies with high ADH activity better tolerate the acetone than flies with low levels of ADH activity (David et al., 1981), both types of flies seem to exhibit a similar tolerance to pentenone (Morgan, 1975; paper in preparation).

As mentioned above, the reduction in isopropanol-mediated $\mathrm{ADH}$ activity and the induction of AKR activity have been interpreted by some authors as having an adaptative significance (Gonzàlez-Duarte and Vilageliu, 1985; Gonzàlez-Duarte and Atrian, 1986). Such a mechanism would protect the flies against the toxic effects of acetone. We have recently shown that after ingesting isopropanol, flies of all three $A d h$ genotypes displayed a much higher sensitivity to ethanol than to isopropanol, although the opposite results were observed in flies not pretreated with isopropanol (Guillén et al., 1987). Our observations that neither pentenol nor pentenone reduce significantly the ADH activity in vivo suggest that this hypothetical adaptative mechanism cannot be extended to all secondary alcohols. Moreover, we must note that although we have observed a weak decrease in ADH activity of flies exposed to pentenone (fig. 1), this compound does not seem to inhibit ADH activity. Thus, when FF flies showing a reduction in isopropanol-mediated ADH activity were afterwards exposed to pentenol or pentenone, a significant increase in ADH activity was detected (fig. 3).

$\mathrm{ADH}$ isozyme interconversion is due to a noncovalent binding of one (ADH-3) or two (ADH-1) molecules of an NAD-carbonyl adduct to the native enzyme (ADH-5) (Schwartz and Sofer 1976; Heinstra et al., 1986c). The exposure of flies to a variety of carbonyl compounds (including acetone), whose structures are similar to the substrates of $\mathrm{ADH}$, resulted in an increase of ADH-1 and ADH-3 forms, and a decrease of the ADH-5 form and total ADH activity (Schwartz and Sofer, 1976; Gonzàlez-Duarte and Atrian, 1986; Heinstra et al., 1986a-c; Guillén et al., 1987). It is quite surprising that neither pentenol nor pentenone alter significantly the relative proportions of isozymes when, besides the carbonyl group of pentenone, pentenol is a good substrate for ADH (Morgan, 1975). All the compounds tested to date that induce $\mathrm{ADH}$ interconversion possess either a secondary alcohol, or a carbonyl group (Schwartz and Sofer, 1976), or a $\beta$-keto group (Heinstra et $a l, 1986 c$ ). Pentenol and pentenone have a secondary alcohol and a carbonyl group, respectively. Nevertheless, the keto group of pentenone is not in the $\beta$ position. As pointed out by Heinstra $e t$ al $(1986 c)$, it is possible that a $\beta$-keto group is a necessary condition to induce the ADH interconversion. It is also possible that the unsaturated nature of pentenol and pentenone is important in the formation of the NAD-carbonyl inhibitory complex. Further studies need to be done to test these hypotheses.

\section{REFERENCES}

ANDERSON, S. M. AND McDONALD, J. F. $1981 a$. A method for determining the in vivo stability of Drosophila alcohol dehydrogenase (EC 1.1.1.1.). Biochem. Genet, 19,411-419.

ANDERSON, S. M. AND McDONALD, J. F. $1981 \mathrm{~b}$. Effect of environmental alcohol on in vivo properties of Drosophila alcohol dehydrogenase. Biochem. Genet., 19, 421-430.

AYAlA, F. J., POWELl, J. R., TRACEY, M. L., MOURÃO, C. A. AND PÉREZ-SALAS, S. 1972. Enzyme variability in the Drosophila willistoni group. IV, Genic variation in natural populationsof Drosophila willistoni. Genetics, 70, 113-139.

BARBANCHO, M., SÁNCHEZ-CAÑETE, F. J. S., DORADO G. AND PINEDA, M. 1987. Relation between tolerance to ethanol and alcohol dehydrogenase (ADH) activity in Drosophila melanogaster: Selection, genotype and sex effects. Heredity, $58,443-450$.

DAVID, J. R., BOCQUET, C., HERREWEGE, J. VAN, FOUILLET, P. AND ARENS, M. F. 1978. Alcohol metabolism in Drosophila melanogaster: Uselessness of the most active aldehyde oxidase produced by the Aldox locus. Biochem. Genet., 16, 203-211.

DAVID, J. R., DALY, K. AND HERREWEGE J. VAN. 1984. Acetaldehyde utilization and toxicity in Drosophila adults lacking alcohol dehydrogenase or aldehyde oxidase. Biochem. Genet., 22, 1015-1029.

DAVID, J. R., HERREWEGE, J. VAN, SCHEEMAEKER-LOUIS, M. DE AND PLA, E. 1981. Drosophila alcohol dehydrogenase: Detoxification of isopropanol and acetone, substances not used in energy metabolism. Heredity, 47, 263-268.

DAY, T. H., HILliER, P. C. AND CLARKE, B. 1974. Properties of genetically polymorphic isozymes of alcohol dehydrogenase in Drosophila melanogaster. Biochem. Genet., 11, 141-153.

DORADO, G. AND BARBANCHO, M. 1984. Differential responses in Drosophila melanogaster to environmental ethanol: Modification of fitness components at the Adh locus. Heredity, 53, 309-320.

EISSES, K. TH., SCHOONEN, W. G. E. J., ABEN, W., SCHARLOO, W. AND THÖRIG, G. E. W. 1985. Dual function of the alcohol dehydrogenase of Drosophila melanogaster: Ethanol and Acetaldehyde oxidation by two allozymes ADH-71k and ADH-F. Mol. Gen. Genet., 199, 76-81.

GONZÀlEZ-DUARTE, R. AND ATRIAN, S. 1986. Metabolic response to alcohol ingestion in Drosophila hydei. Heredity, $56,123-128$.

GONZÀlEZ-DUARTE, R. AND VILAGELIU, LI. 1984. Metabolic response to ethanol and isopropanol in $D$. funebris and $D$. immigrans. Comp. Biochem. Physiol., 80C, 189-193.

GONZÀlEZ-DUARTE, R. AND VILAGELIU, LI. 1985. Metabolic response to ethanol and isopropanol in $D$. funebris and $D$. immigrans. Comp. Biochem. Physiol., 80C, 189-193.

GUilléN, E., SÁNCHEZ-CAÑETE, F. J. S., GARRIDO, J. J., DORADO, G. AND BARBANCHO, M. 1987. Intergenotypic effect of Isopropanol ingestion in the further detoxification of ethanol and isopropanol in Drosophila melanogaster. Heredity, 59, 405-411. 
HEINSTRA, P. W. H., ABEN, W. J. M., SCHARL.OO, W. AND THÖRIG, G. E. W. 1986a. Alcohol dehydrogenase of Drosophila melanogaster: Metabolic differences mediated through cryptic allozymes. Heredity, 57, 23-29.

HEINSTRA, P. W. H., EISSES, K. Th., SCHARLOO, W. AND THÖRIG, G. E. W. 1986b. Metabolism of secondary alcohols in Drosophila melanogaster: Effects on alcohol dehydrogenase. Comp. Biochem. Physiol., 83B, 403-408.

HEINSTRA, P. W. H., EISSES. K. TH., SCHOONEN, W. G. E. J., ABEN, W., WINTER, A. J. DE, HORST, D. J. VAN DER, MARREWIJK, W. J. A. VAN, BEENAKKERS, A. M. TH., SCHARLOO, W. AND THÖRIG, G. E. W. 1983. A dual function of alcohol dehydrogenase in Drosophila. Genetica, 60, 129-137.

HEINSTRA, P. W. H., SCHARLOO, W. AND THÖRIG, G. E. W. 1986c. Alcohol dehydrogenase of Drosophila: Conversion and retroconversion of isozyme patterns. Comp. Biochem. Physiol., 83B, 409-414.

HERREWEGE, J. VAN, DAVID, J. R. AND GRANTHAM, R. 1980. Dietary utilization of aliphatic alcohols by Drosophila. Experientia, 36, 846-847.

MIDDLETON, R. J. AND KACSER, H. 1983. Enzyme variation, metabolic flux and fitness: Alcohol dehydrogenase in Drosophila melanogaster. Genetics, 105, 633-650.

MORGAN, P. 1975. Selection acting directly on an enzyme polymorphism. Heredity, 35, 124-127.

MOXOM, L. N., HOLMES, R. S., PARSONS, P. A., IRVING, M. G. AND DODDRELL, D. M. 1985. Purification and molecular properties of alcohol dehydrogenase from Drosophila melanogaster: Evidence from NMR and kinetic studies for function as an aldehyde dehydrogenase. Comp. Biochem. Physiol., 80B, 525-535.
OAKESHOTT, J. G. 1977. Variation in the direction of selection applied by pentenol to the alcohol dehydrogenase locus in Drosophila melanogaster. Aust. J. Biol. Sci., 30, 259-267.

O'DONNEL.L, J., GERACE, L., LEISTER, F. AND SOFER, W. 1975. Chemical selection of mutants that affect alcohol dehydrogenase in Drosophila. II, Use of 1-pentene-3-ol. Genetics, 79, 73-83.

PAPEL, I., HENDERSON, M., HERREWEGE, J. VAN, DAVID, J. AND SOFER, W. 1979. Drosophila alcohol dehydrogenase activity in vitro and in vivo: Effects of acetone feeding. Biochem. Genet., 17, 553-563.

SÁNCHEZ-CAÑETE, F. J. S., DORADO, G. AND BARBANCHO, M. 1986. Ethanol and isopropanol detoxification associated with the Adh locus of Drosophila melanogaster. Heredity, 56, 167-175.

SCHWARTZ, M., O'DONNELl., J. AND SOFER, W. 1979. Origin of the multiple forms of alcohol dehydrogenase from Drosophila melanogaster. Arch. Biochem. Biophys., 194, 365-378.

SCHWARTZ, M. AND SOFER, W. 1976. Diet-induced alterations in distribution of multiple forms of alcohol dehydrogenase in Drosophila. Nature, 263, 129-131.

SOFER, W. H. AND HATKOFF, M. A. 1972. Chemical selection of alcohol dehydrogenase negative mutants in Drosophila. Genetics, 72, 545-549.

VILAGELIU, LI. AND GONZÀl.EZ-DUARTE, R. 1980. Effect of ethanol and isopropanol on the activity of alcohol dehydrogenase, viability and life-span in Drosophila melanogaster and Drosophila funebris. Experientia, 36, 828-829. 